\title{
Case Study of the Insured Persons Satisfaction with the Assistance Centre
}

\author{
ALEKSANDER JANEŠ \\ University of Primorska, Slovenia \\ aleksander.janes@fm-kp.si \\ MARTINA FRANČE ŠKIN \\ Triglav, Zdravstvena zavarovalnica, Slovenia \\ martina.franceskin@triglavzdravje.si
}

\begin{abstract}
The purpose of the presented paper is to discuss on the factors that influence the satisfaction of the insured persons with the assistance centre (AC) of the investigated health insurance company. In the empirical part of the research the factors which are important for the satisfaction of the insured with the Ac were investigated with the questionnaire for insured persons. The factor that is the most statistically positively related to user satisfaction is the 'understanding the needs and requirements of policyholders'. Based on the findings from empirical research (questionnaire for insured persons and interview with Ac's employees), improvement proposals were defined which should increase the satisfaction of policyholders with the Ac's service. Recognized findings and suggestions should be considered and reasonably implemented by the insurance policy designers.
\end{abstract}

Key words: Health Insurance Company, insured persons, process management, policyholders, satisfaction

(cc)BY-SA https://doi.org/10.26493/1854-4231.15.121-136

\section{Introduction}

Health is the highest value in modern society, as it is the first condition for increasing well-being. The company needs to take care of the right environmental conditions as these are a prerequisite for maintaining and promoting health (Svetovna zdravstvena organizacija 2014). Due to the current topic of population aging and the consequent increase in the morbidity and mortality of people and the nature of work, the investigation focused on the satisfaction of insured persons with the assistance centre (AC) of the selected health insurance company. It is a well-known fact that waiting times for specialist examinations, diagnostics and public health interventions 
in Slovenia are increasing and as a consequence, people's dissatisfaction is increasing (Nacionalni inštitut za javno zdravje 2019). As a result of this, more and more people are opting to buy additional health insurance, which allows policyholders to have shorter waiting times for medical treatment.

The official records of the selected insurer show that the growth of supplementary health insurance has increased dramatically from 2013 to the present, with the increase in claims of insured persons through the AC (Triglav zdravstvena zavarovalnica 2016). It was this fact that prompted investigation of the insured persons satisfaction with the AC and which are the important factors to the satisfaction of the insured persons with the Ac.

\section{Literature Review}

Call centres accept calls and forward them to the assistance centre based on insured's requests for assistance. In assistive centres, employees are prompted for appropriate treatment based on the nature of the call. The Assistance Centre is thus an indispensable part of the insurance industry, whose core business is managing sudden and unexpected events. Insurance companies provide assistance in various areas such as: home assistance, car assistance, medical assistance. Assistant centre employees offer a wide variety of invisible services to users. They can only provide information about the desired assistance service or assistance as a service (Rolland et al. 2006).

Ac's employees are required to always have a friendly voice when in contact with the insured. It is a well-known fact that working in an AC is characterized by routine tasks and a high level of stress and a low level of control for employees in terms of work tasks and interaction with clients. Ferreira et al. (2015) describe the purpose of establishing assisted care centres designed for the insureds' or patients' needs and contributing to the overall satisfaction of citizens with the health care system and its effectiveness.

Mazzucato, Houyez, and Facchin (2014) and Nayak, Bhattacharyya, and Krishnamoorthy (2019) emphasize the need for telephone services that are parallel to other information systems. Parallel to the online providers of information on health advice or health services, information services have been introduced, i.e. assistance centres, based on telephone communication. Assistance centres have been designed as an alternative information access point for patients with rare diseases (Babac et al. 2018).

The Ac of the selected Health insurance Company alias insurer 
started operating in 2013. It was also the first time that additional health insurance was taken out. Due to the small number of insured persons with supplementary health insurance, the need for assistance workers was low. Only a graduate nurse and other administrative employees were employed. With the surging growth in supplementary health insurance policies, in 2016 the employees at the AC increased to three employees with different health backgrounds. In 2019, there are six health professionals with different health backgrounds in the Ac. Zichello and Sheridan (2008) consider that most frequently employed nursing assistantships in the European Union $(\mathrm{EU})$ are registered nursing graduates who direct policyholders to appropriate medical treatment. If the patient's condition does not require the judgment of a physician on call, the graduate nurse often contacts the insured person only by telephone counselling. In Norway, the system is organized in the municipal-owned primary care sector. The system serves as the protector of the secondary health services of state-owned hospitals. Medical responsibility for medical services is largely assumed by general practitioners who alternate in their area. Nursing assistance represents an important part of primary health care services. Medical assistance is an important and extensive activity that educates and advises patients, healthcarers and relatives. As a result, the workload of clinics is reduced (Midtbø, Raknes, and Hunskaar, 2017).

The selected Ac of the insurer employs six people with a medical degree, one graduate nurse, two graduate medical doctors, one master of nursing, one master of education and health management and a medical technician. The work tasks of employees are arranged according to internal duties and assigned tasks in the Ac. One of the key tasks of the help centres is to talk or counselling on health and psychosocial issues. Research has shown that telephone lines are needed for help or personal contact. Patients with chronic illnesses or relatives want telephone counselling led by medical professionals with broad healthcare competencies. Acs are created to assist patients and provide broad spectrum information on health and psychosocial issues (Adam et al. 2012; Babac et al. 2018; Ekberg et al. 2014). Beesley et al. (2010) describe the introduction of an AC that offers exclusive telephone counselling. Telephone counselling differs from assistance depending on the type of information provided, such as references, counselling and or medical information. Zichello and Sheridan (2008) stated that health education in EU countries plays an important role in health insurance companies. They researched that graduating a nurse by adapting an insurance plan would have 
an impact on managing claims and improving the safety of insured persons. Ratanawongsa et al. (2012) describe that nursing graduates engage in supportive education for the insured persons to manage and manage chronic illnesses. Wiener and Gilliland (2011) found the importance of properly documenting the insured person's medical treatment and care of the medical records. They found that nursing graduates care was in line with standards set by regulations and professional ethical expectations (Cartwright-Vanzant 2010).

The work process at the Ac is defined as a sequence of work procedures and activities, which is integrated into the comprehensive process (Gošnik 2019) of the selected insurance company. The activities of this process are directly related to the insurance or the enforcement of the contractually agreed liabilities of the insurance company on the basis of covered risks insurance, which represents the 'insurance case' and the liability to the insured (Triglav zdravstvena zavarovalnica 2013).

For information on registering an insurance case, the insured person calls the call centre, which gives him instructions on registering or announcing the insurance case. For more detailed explanations of the medical personnel, the call centre connects the call of the insured person to the AC where they are employed with medical knowledge. They provide policyholders with information, advice on health issues, insurance-related information, and health care providers. When exercising supplementary health insurance rights, registration or announcement of the desired health service to the AC is required. Insured persons have the option of announcing or registration of the insurance case by e-mail, telephone call (Mevissen et al. 2012) and in writing via regular paper mail. Upon arrival of the announcement or registration of the insurance case, the latter is automatically transferred to the program where the documentation is stored. The employee in charge of the program, where case is managed and stored without paper documentation, assigns insurance claims to employees at the Ac. Employees with health education are involved in the treatment at the AC. The Ac organizes the terms of medical treatment on the basis of the obtained medical documentation and the wishes of the insured person, issues the consent on the implementation of the provided health services, prepares reimbursements of insurance cases and provides assistance in exercising rights.

The employees at the Ac have different health education and different job responsibilities and competences (Bach and Suliková 2019). When dealing with an insurance case, in addition to qual- 
ity nursing care, employees at the Ac must also include insurance skills in the process, as all insurances have different limitations on the insurer's obligations. Ac's employees must adapt to insurance when dealing with an insurance case, since insurance is limited in content or coverage.

When dealing with an insurance case, the employees at the Ac must verify the formal, procedural and substantive relevance of the insurance case. With the help of a computer program (Rath and Pattanayak 2019), the employee verifies all the rights in the existing insurance and then proceeds with the case. If it finds deviations in formal, procedural or substantive inadequacy, it calls the insured person and dismisses the case in the computer program and informs the administrative employees to send a rejection notice.

When ordering the insured person for the intended health care services, the employees of the Ac play an important role, since they provide the insured person with information about the order for investigation or specialist examinations or interventions. When ordering an insured person for the planned health service, employees of the Ac take into account the time and place restrictions of the insured person. They provide the insured person with information on possible preparations for investigations and assist in the interpretation and fulfilment of various investigations or interventions. They are in close contact with healthcare providers, as they wish to provide comprehensive assistance to policyholders at the Ac.

On the basis of mutual internal agreements between the employees of the AC and prior communication with the insured person and with health care providers, they advise the insured person about possible diagnostics before specialist examinations. With the help of the latter's agreed method of work and internal arrangements of employees and communication with health care providers, they speed up health care and shorten the insured's time to the final diagnosis.

After completing the order for the planned examination or diagnostics or intervention, the employee in the Ac prepares the authorization in the computer program for the intended health service of the insured person. For the traceability of health treatments, the AC has a computer program (Rath and Pattanayak 2019) in which all information about the treatment of an insurance case is entered from the date of announcement to the date of completion of the medical treatment.

After expert processing of the insurance case and preparation of authorization in the Ac, the latter is handed over to the administrative employees who arrange for the dispatch of the authorization. 
The administrative employees send the authorization to the insured person in electronic form or in physical form via regular mail, according to the insured person's request.

\section{Methodology}

The purpose of the research was to gain in-depth insight into the work process (Gošnik 2019) of the Ac of the selected health insurance company case study (Gummesson 2000) and to research and analyse the satisfaction of the insured persons with the Ac services. For that purpose the following research questions $(\mathrm{RQ})$ were defined:

$\mathrm{RQ} 1$ What importance do the insured persons attribute to the assistance centre?

$\mathrm{RQ} 2$ What factors are important to the satisfaction of policyholders?

$\mathrm{RQ} 3$ How to increase the satisfaction of the insured persons with the help centre?

$\mathrm{RQ} 4$ How to improve the work process in the assistance centre?

A survey of the AC users with a survey questionnaire was conducted. The author's original questionnaire was created using the $1 \mathrm{ka}$ (https://www.1ka.si) website. The online survey questionnaire was active on med.over.net and mojforum.si forums and on social networks from May 23, 2019 to August 22, 2019. The sample of respondents was occasional, which is an unrepresentative sample. During the three-month period, 117 people activated questionnaire online; 74 questionnaires from Ac users were submitted, of which two were only partially completed. The completed questionnaires about satisfaction data of 72 respondents were used in the analysis.

The survey comprehended 52 women's i.e. $72.22 \%$ of all respondents, and 20 men's i.e. $27.78 \%$ of all respondents. Most respondents were between 41 and 50 years old. The structure of the respondents' education is usually higher education or university education, or as much as $50 \%$ of all participants.

Based on the obtained demographic data of the respondents, it can be concluded that the majority of additional health insured is from central Slovenia, that there are highly educated, married and aged between 41 to 50 years. From this it can be concluded that the insured are middle-aged, have a good economic standard and want to create a secure future in the event of potential health problems. Purchasing additional health insurance allows them to have a quick medical treatment and, consequently, to obtain a final diagnosis quickly. 
Beside the questionnaire for Ac users, the interview with the six employees focus group was performed (Adam et al. 2012).

\section{Empirical Findings and Discussion}

\section{ANALYSIS OF THE ASSISTANCE CENTRE RESPONSE}

In the survey the responsiveness of the Ac in relation to the medical records provided via e-mail, mobile application and telephone call to the Ac was analysed. The data, together with the frequency of calls and call times, served as information about when the AC was the busiest and whether the work process was still optimal with regard to the growth of insured persons.

Most of the insured persons surveyed communicated with the AC via telephone, i.e. $97.78 \%$ of all, and send the documentation via email, i.e. $87.67 \%$ of all. The insured's medical records were emailed to $87.67 \%$, followed by a call to the Ac. Considering that $10.11 \%$ of the insured persons did not send medical records via e-mail, but only called the Ac, it can be concluded that they wanted only general information or information on exercising rights or some other information related to assistance. Namely, claiming insurance rights requires the registration or announcement of an insurance case, and a medical indication is required, which is sent by insured persons by e-mail or regular mail.

The most common answer given by the respondents regarding the Ac call back time was up to 1 hour, which was answered by $29.23 \%$ of all respondents. This, in descending order, is followed by the answers that they had to wait up to 15 minutes, $26.15 \%$, followed by $15.38 \%$ of the respondents who were waiting for the call until the next day. $12.31 \%$ of the respondents were called back immediately and $10.77 \%$ of respondents received a call back within two hours. The fewest respondents claimed to have waited either 4 hours or 8 hours - two participants in each case, which is $3.08 \%$ of all in both cases.

Regarding the frequency of calls to the $\mathrm{Ac}$, the majority of participants answered that they had called or sent medical records between 10:01 and 14:00 hours. Such responses were as high as $64.18 \%$. The descending order is followed by the answers regarding last calls times: from 6:00 to $10: 00$ with $20.9 \%$ and in the penultimate place from $14: 01$ to $18: 00$ with $11.94 \%$. Last calls time was from 18:01 to 22:00 with only two answers, representing $2.99 \%$.

Through interview with the Ac employee focus group, we obtained information that they have the highest frequency of work between 10:00 and 14:00. During this time, a lunch break with a sliding sched- 
ule takes place for employees. Due to this fact, employees think that, as a result, it is very likely that the call back time will be extended. Through the interview of the Ac employee's focus group, we found that all employees have a consensus that the work process is not optimal and that a work process audit is needed. They unanimously believe that the rapid growth of policyholders has led to an increase in the volume of work and consequently led to a sub-optimal work process.

\section{ANALYSIS OF RESEARCH QUESTIONS AND DISCUSSION}

Regarding the research question RQ1, 'What importance do the insured persons attribute to the assistance centre?' two sets of questions were used:

1. Ac Service Satisfaction, and

2. The characteristics of the employees in the Ac.

The first set about the ac services included twelve questions, which could had been answered by a choice on a six-point Likert scale: I would not know, Very bad, Bad, Neither good nor bad, Good, Very good (table 1 ).

The most important assistance service according to policyholders is receiving clear guidance on the healthcare provider (83.33\%). Another assistance service that is very important to policyholders is the receipt of clear medical treatment instructions (81.54\%).

The surveyed policyholders expressed a poor opinion about the telephone connection (63.64\%) and the explanation of the envisaged further treatment of the insured (64.18\%). With these two services, the insured are the least satisfied.

This can be related to the fact that the maximum frequency of work in the AC is between 10:00 and 14:00 hours and that during this time the most insured persons waited for the call of the assistants for as much as 1 hour. This fact confirms that AC is the busiest during this time, and that work reorganization is needed to ensure policyholders satisfaction with AC responsiveness.

The second set about the characteristics of the employees in the Ac included eleven questions, which could had been answered by a choice on a six-point Likert scale: I would not know, It doesn't matter at all, Little important, Important, Very important, Especially important (table 2).

As seen from table 2 the most important attribute for the surveyed, is the employee's communication skills (61.19\%), and followed by the knowledge regarding the exercise of rights from supplementary 
TABLE 1 Frequency Analysis of Ac Service Metrics

\begin{tabular}{lrrrrrr}
\hline Question & $(1)$ & $(2)$ & $(3)$ & $(4)$ & $(5)$ & $(6)$ \\
\hline $\begin{array}{l}\text { Do you think that the employee has } \\
\text { deepened enough in your problem? }\end{array}$ & 70.42 & 28.17 & 0.00 & 0.00 & 0.00 & 1.41 \\
\hline $\begin{array}{l}\text { The employee was considerate, respect- } \\
\text { ful and listened to you? }\end{array}$ & 77.61 & 20.9 & 1.49 & 0.00 & 0.00 & 0.00 \\
\hline $\begin{array}{l}\text { Were you explained the purpose of the } \\
\text { medical treatment and any further proce- }\end{array}$ & 64.18 & 28.36 & 1.49 & 1.49 & 0.00 & 4.48 \\
dures, interventions? & & & & & & \\
\hline $\begin{array}{l}\text { Has the ordered treatment been carried } \\
\text { out in accordance with your expecta- } \\
\text { tions? }\end{array}$ & 72.73 & 24.24 & 0.00 & 0.00 & 0.00 & 3.03 \\
\hline $\begin{array}{l}\text { Were you involved in deciding about your } \\
\text { treatment? }\end{array}$ & 75.38 & 21.54 & 0.00 & 0.00 & 0.00 & 3.08 \\
\hline $\begin{array}{l}\text { Did you easily get a phone connection } \\
\text { with the Ac? }\end{array}$ & 63.64 & 19.70 & 9.09 & 1.52 & 0.00 & 6.06 \\
\hline Did you get the information you needed? & 74.24 & 24.24 & 0.00 & 0.00 & 0.00 & 1.52 \\
\hline $\begin{array}{l}\text { Did you receive clear instructions on the } \\
\text { selected healthcare provider? }\end{array}$ & 83.33 & 16.67 & 0.00 & 0.00 & 0.00 & 0.00 \\
\hline $\begin{array}{l}\text { Did you receive clear instructions regard- } \\
\text { ing medical treatment? }\end{array}$ & 81.54 & 15.38 & 0.00 & 0.00 & 0.00 & 3.08 \\
\hline $\begin{array}{l}\text { Do you think the employee explained the } \\
\text { matter/treatment/information that you } \\
\text { have understood? }\end{array}$ & 74.24 & 22.73 & 1.52 & 0.00 & 0.00 & 1.52 \\
\hline $\begin{array}{l}\text { Do you think that the employee stimu- } \\
\text { lated your confidence? }\end{array}$ & 77.61 & 22.39 & 0.00 & 0.00 & 0.00 & 0.00 \\
\hline $\begin{array}{l}\text { Do you think the employee is profession- } \\
\text { ally qualified for the job? }\end{array}$ & 71.21 & 27.27 & 0.00 & 0.00 & 0.00 & 1.52 \\
\hline
\end{tabular}

Notes Column headings are as follows: (1) very good, (2) good, (3) neither good nor bad, (4) bad, (5) very bad, (6) i would not know. In percent.

health insurance $(52.17 \%)$. In most cases, the gender $(71.01 \%)$ and age $(56.52 \%)$ of the employee were chosen as an insignificant feature of the Ac's employees.

Proper handling of insurance cases requires extensive healthcare knowledge and work experience in various health fields. Insured persons do not feel that the qualities of the employees at the Ac are important. The most important feature of assisting users is the communication skill of the help desk employees. The first contact of the insured person with the employee at the Ac is interpersonal contact and communication. Insured persons are not aware of the importance of a broad knowledge of healthcare and work experience of employees, as this enables them to properly refer the insured to the intended medical treatment. At the same time, a great deal of work 
TABLE 2 AC Employee's Characteristics

\begin{tabular}{lrrrrrrr}
\hline Question & & $(1)$ & $(2)$ & $(3)$ & $(4)$ & $(5)$ & $(6)$ \\
\hline Occupation of an employee & $N$ & 24 & 20 & 16 & 4 & 2 & 5 \\
& $\%$ & 33.8 & 28.17 & 22.54 & 5.63 & 2.82 & 7.04 \\
\hline The gender of the employee & $N$ & 2 & 2 & 5 & 7 & 49 & 4 \\
& $\%$ & 2.9 & 2.9 & 7.25 & 10.14 & 71.01 & 5.8 \\
\hline Employee age & $N$ & 4 & 3 & 12 & 5 & 39 & 6 \\
& $\%$ & 5.8 & 4.35 & 17.39 & 7.25 & 56.52 & 8.7 \\
\hline Medical knowledge & $N$ & 24 & 17 & 17 & 4 & 2 & 5 \\
& $\%$ & 34.78 & 24.64 & 24.64 & 5.8 & 2.9 & 7.25 \\
\hline Employee education level & $N$ & 12 & 14 & 20 & 9 & 7 & 7 \\
& $\%$ & 17.39 & 20.29 & 28.99 & 13.04 & 10.14 & 10.14 \\
\hline At least 5 years of work experience & $N$ & 16 & 15 & 15 & 11 & 6 & 6 \\
in healthcare & $\%$ & 23.19 & 21.74 & 21.74 & 15.94 & 8.7 & 8.7 \\
\hline Employee knowledge of health care & $N$ & 20 & 21 & 20 & 4 & 0 & 3 \\
legislation & $\%$ & 29.41 & 30.88 & 29.41 & 5.88 & 0 & 4.41 \\
\hline Employee creativity & $\%$ & 17 & 23 & 17 & 5 & 0 & 4 \\
\hline IT knowledge of employee & $\%$ & 25.76 & 34.85 & 25.76 & 7.58 & 0 & 6.06 \\
\hline Knowledge of exercising supplemen- & $N$ & 36 & 23 & 7 & 0 & 0 & 3 \\
tary health insurance rights & $N$ & 11 & 25 & 24 & 4 & 1 & 4 \\
\hline Communication skills & $N$ & 41 & 24 & 1 & 0 & 0 & 1 \\
& $\% 1.19$ & 35.82 & 1.49 & 0 & 0 & 1.49 \\
\hline
\end{tabular}

Notes Column headings are as follows: (1) especially important, (2) very important, (3) important, (4) little important, (5) it doesn't matter at all, (6) I would not know.

experience in various fields of health care helps to interpret correctly the intended health treatment of the insured person.

Research questions RQ2 and RQ3 were examined using the factor analysis. First, all the sets of questions that were related to the satisfaction of the insured with the Ac were identified:

- estimated time of insurance case resolution (4 sub-sets);

- evaluation of the Ac properties (11 sub-sets);

- evaluation of satisfaction with Ac services (7 sub-sets);

- Ac's Quality Assessments (13 sub-sets).

Respondents were able to answer each of the sub-sets by a choice on a five-point Likert scale: Very unsatisfied, I'm not satisfied, Neither satisfied nor dissatisfied, Satisfied, Very satisfied.

Before performing the factor analysis, the data were analysed with a Pearson correlation test. The results showed that some values have 
TABLE 3 Spearman Correlation Coefficient

\begin{tabular}{lrr}
\hline Item & $r$ & $p$ \\
\hline Accuracy in the management of insured data & 0.640 & $<0.001$ \\
Understanding the needs and requirements of policyholders & 0.700 & $<0.001$ \\
Fulfilment of promises, agreements & 0.436 & 0.006 \\
Transparency of authorization & 0.682 & $<0.001$ \\
Transparency of cover letters & 0.684 & $<0.001$ \\
Access to the appropriate contact person & 0.622 & $<0.001$ \\
Phone response speed & 0.658 & $<0.001$ \\
Complaints handling & 0.282 & 0.112 \\
Resolving reclamation & 0.233 & 0.192 \\
Informing policyholders & 0.502 & 0.001 \\
\hline
\end{tabular}

Notes Due to the space limitation of paper, only Spearman's analysis is shown because the table of Factors of Satisfaction with the Ac is extensive.

a strong correlation $(r>0.8)$, which is present in questions of the same set. Some measurements, however, either have no statistically significant association (statistical significance $p>0.05$ ) or have a very weak correlation $(r<0.2)$, which is present for questions from different sets.

In order to get one measurement i.e. factor which represents satisfaction of respondents with AC, exploratory factor analysis of all sub-sets was performed. The recognized factor was called satisfaction. The principal axis factoring method was used to find the satisfaction factor. In order to rotate the factor model estimation the Varimax method was used. When constructing the factors, the standard limit of 0.3 for the factor weights was used, so the following variables have fallen out: time to reject insurance, time to resolve complaints, resolve complaints and resolve reclamation.

The result of Bartlett's test of sphericity indicates that the variables are interrelated and the factor obtained is valid $(p<0.05)$. The obtained factor explains as much as $40.2 \%$ of the variance of satisfaction of all respondents.

In reviewing the correlations of satisfaction with AC a non-parametric test was used, i.e. Spearman Correlation Test, which results are presented in table 3 .

Based on the analysis, the response to RQ2 refers to variables that are statistically significantly related to user satisfaction. The strongest positive correlation with satisfaction and understanding of the needs and requirements of the insured persons is the strongest $(r=0.7)$. This is followed by transparency of cover letters $(r=0.684)$ and authorization review $(r=0.682)$. Of all the factors that are statis- 
tically significantly related to insured's satisfaction, the weakest correlation has the fulfilment of promises and agreements $(r=0.436)$.

To find the answer to RQ3's research question on how to increase Ac user's satisfaction, a factor analysis results were used to identify the satisfaction factor. Variables with the highest factors weights value, which also have the greatest impact on Ac user satisfaction, are:

- explaining the purpose of the treatment and possible follow-up procedures, interventions (0.942);

- ordered treatment was performed as expected (0.859);

- understanding the needs and requirements of policyholders (0.829).

With increased attention to these aspects, insureds' satisfaction with AC would also increase the most. Therefore, when dealing with an AC insurance case, it is very important to focus on an in-depth explanation to policyholders of what the purpose or the intended treatment is (0.942). It should be emphasize the importance of many years of work experience of health care professionals in Ac and the importance of knowledge of different fields of work, since the latter contributes to the proper health treatment of the insured.

The satisfaction of the insured with the Ac is also greatly influenced by the expectation of ordered medical treatment (0.859). This variable is also confirmed by the fact that it is very important for the insured person to explain the course of the medical treatment before the hearing, so that he or she can create a realistic expectation of the intended health service.

The third most important variable, for the satisfaction of policyholders with Ac, is in understanding the needs and requirements of policyholders (o.829). This variable is strongly related to the communication skills of Ac employees, since only good communication between the insured person and the Ac employee can ensure a proper understanding of the insured's needs and desires and, consequently, lead to a satisfied insured person.

Regarding the RQ4 research question, 'How to improve the work process in the assistance centre?' focus group interview was performed. In order to obtain an answer to the RQ4, the internal documents of the selected insurance company on the work process of the AC (Triglav zdravstvena zavarovalnica 2013) was reviewed. With the help of interview with the Ac's employees, the opinions of about the work process in the Ac from another perspective were gained and improvement proposals were defined as follows: 
- Continuous education of employees in the Ac on communication skills;

- Focus on the needs/wishes/requirements of policyholders regarding health care providers;

- Orientation towards the needs/wishes/requirements regarding the interpretation of the envisaged health services;

- Updating the computer program to speed up the handling of insurance cases;

- Updating of a computer program for automated verification of the formal, substantive, procedure suitability of insurance cases;

- For faster response of the Ac to move lunch time for employees with a non-slip schedule;

- To include additional employees in the ac during the maximum frequency of calls, who would receive calls and, based on callers needs address the needs of policyholders as a matter of priority;

- Additional training of call centre employees would also contribute to a faster response of the Ac, as certain information would be processed at the level of the call centre. As a result, there would be fewer calls to the Ac during the busiest hours;

- To employ additional medical staff in the Ac (the most expensive proposal).

Findings and improvement proposals can be tied to several researches about; training and education of employees (CartwrightVanzant 2010; Mevissen et al. 2012; Zichello and Sheridan 2008), focus on the needs/wishes/requirements of policyholders (Adam et al. 2012; Ferreira et al. 2015), computer programs (Rath and Pattanayak 2019), and additional employees (Ekberg et al. 2014 by Babac et al. 2019).

\section{Conclusion}

The case study focused on the satisfaction of the insured with AC of the selected insurance company. Through the method of surveying the insured persons, in-depth insight into the satisfaction of AC users was gained. Through a focus group interview of Ac employees, an employee opinion on the impact of the work process on the satisfaction of the insured persons was obtained (Adam et al. 2012). The study confirmed the opinion of the Zichello and Sheridan (2008) that health-educated personnel play a very important role in health insurance companies in dealing with insurance cases. Used Triangulation (interview, questionnaire for insured persons and documents 
analysis) in the survey allowed to obtain opinions from different perspectives on the important attributes of employees with health education at the assisting centre, as these influence the reflection of the satisfaction of the insured persons.

Interview with employees of the Ac revealed that the work process was not optimal due to the rapid increase of the insurance cases. They believe that changes in the work process and upgrading of the information system are needed to facilitate and faster handling of insurance cases. Based on the answered questionnaires of Ac users, it was found that the insured persons did not feel the lack of efficiency of the working process (Novak and Janeš 2019) in the AC when dealing with insurance cases.

Investigation supported findings on answers to research questions $(\mathrm{RQ})$ : Answer to RQ1 led to the realization that it is important for the insured persons to receive clear instructions on the desired service or health care provider. Regarding the answer to RQ2: The factor that is the most statistically positively related to user satisfaction is the 'understanding the needs and requirements of policyholders'. Answer to third RQ3 was achieved with findings on the most influential factors regarding the satisfaction of the insured (explaining the purpose of the treatment and possible follow-up procedures, interventions (0.942); ordered treatment was performed as expected (0.859); understanding the needs and requirements of policyholders (0.829); table 3). Answer to research question RQ4, was found through focus group interview with AC employees and review of the internal documentation of the insurance company (Triglav zdravstvena zavarovalnica 2013). Based on the obtained answers to the research questions suggestions for improvements were made out.

The high level of satisfaction of the insured with the Ac will probably also mean the expansion of new insured persons with additional health insurance. As a result, it will affect faster specialist treatment and faster diagnosis for policyholders. However, directly raising the insured persons of the selected insurance company will contribute to lower mortality of the population, as they will be faster to get diagnoses or treatment (Mold 2017).

Presented research has also some limitations: Firstly the survey period was limited by time and relatively small sample of respondents; and secondly investigation considers only one health insurance Company. Research on the factors that influence the satisfaction of the insured persons with the Acs should be extended to other health insurance companies on Slovenian and EU markets in order to acquire new insights and findings.

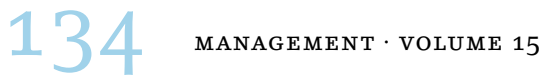




\section{References}

Adam, F., V. Hlebec, M. Kavčič, U. Lamut, M. Mrzel, D. Podmenik, T. Poplas-Susič, D. Rotar-Pavlič, and I. Švab. 2012. Qualitative Research in an Interdisciplinary Perspective. Ljubljana: Institute for Development and Strategic Analysis.

Babac, A., M. Frank, F. Pauer, S. Litzkendorf, D. Rosenfeldt, V. Lührs, L. Biehl, T. Hartz, H. Storf, F. Schauer, T. O. F. Wagner, and J.-M. Graf von der Schulenburg. 'Telephone Health Services in the Field of Rare Diseases: A Qualitative Interview Study Examining the Needs of Patients, Relatives, and Health Care Professionals in Germany.' вмс Health Services Research 18 (1): 99. https://doi.org/10.1186/ S12913-018-2872-9.

Bach, C., and R. Suliková. 2019. 'Competence Development in Theory and Practice: Competence, Meta-Competence, Transfer Competence and Competence Development in Their Systematic Context.' Management 14 (4): 289-304.

Beesley, V. L., M. Janda, E. G. Eakin, J. F. Auster, S. K. Chambers, J. F. Aitken, and D. Battistutta. 2010. 'Gynecological Cancer Survivors and Community Support Services: Referral, Awareness, Utilization and Satisfaction.' Psycho-Oncology 19 (1): 54-61.

Cartwright-Vanzant, R. C. 2010. 'Medical Record Documentation: Legal Aspects in Neonatal Nursing.' Newborn and Infant Nursing Reviews 10 (3): $134-37$.

Ekberg, K., J. McDermott, C. Moynihan, L. Brindle, P. Little, and G. M. Leydon. 2014. 'The Role of Helplines in Cancer Care: Intertwining Emotional Support with Information or Advice-Seeking Needs.' Journal of Psychosocial Oncology 32 (3): 359-81.

Ferreira, R., A. Marques, A. Mendes in J. A. da Silva. 2015. 'Rheumatology Telephone Advice Line - Experience of a Portuguese Department.' Acta Reumatologica Portuguesa 40 (2): 163-68.

Gošnik, D. 2019. 'Core Business Process Management and Company Performance.' Management 14 (1): 59-86.

Gummesson, E. 2000. Qualitative Methods in Management Research. Thousand Oaks, ca: Sage Publications.

Mazzucato, M., F. Houyez, and P. Facchin. 2014. 'The Importance of Helplines in National Plans.' Orphanet Journal of Rare Diseases 9 (1): 37 .

Mevissen, F. E., E. Eiling, A. E. Bos, B. Tempert, M. Mientjes, and H. P. Schaalma. 2012. 'Evaluation of the Dutch AIDS STI Information Helpline: Differential Outcomes of Telephone versus Online Counselling.' Patient Education and Counseling 88 (2): 218-23.

Midtbø, V., G. Raknes, and S. Hunskaar. 2017. 'Telephone Counselling by Nurses in Norwegian Primary Care Out-of-Hours Services: A CrossSectional Study.' вмс Family Practice 18 (1): 84. https://doi.org/10 .1186/s12875-017-0651-z. 
Mold, J. 2017. 'Goal-Directed Health Care: Redefining Health and Health Care in the Era of Value-Based Care.' Cureus 9 (2): e1043. https://doi .org/10.7759/cureus.1043.

Nacionalni inštitut za javno zdravje. 2019. 'National Monitoring of Waiting Times.' http://www.nijz.si/sites/www.nijz.si/files/publikacije -datoteke/porocilo_enarocanje_1.11.2018.pdf.

Novak, R., and A. Janeš. 2019. 'Business Process Orientation in the Slovenian Power Supply.' Business Process Management Journal 25 (4): 780-98.

Nayak, B., S. S. Bhattacharyya, and B. Krishnamoorthy. 2019. 'Application of Digital Technologies in Health Insurance for Social Good of Bottom of Pyramid Customers in India.' International Journal of Sociology and Social Policy 39 (9-10): 752-72.

Ratanawongsa, N., M. A. Handley, J. Quan, U. Sarkar, K. Pfeifer, C. Soria and D. Schillinger. 2012. 'Quasi-Experimental Trial of Diabetes Self-Management Automated and Real-Time Telephonic Support (smartsteps) in a Medicaid Managed Care Plan: Study Protocol.' Bмc Health Services Research 12 (1): 1-13.

Rath, M., and B. Pattanayak. 2019. 'Technological Improvement in Modern Health Care Applications Using Internet of Things (IoT) and Proposal of Novel Health Care Approach.' International Journal of Human Rights in Healthcare 12 (2): 148-62.

Rolland, E., K. M. Moore, V. A. Robinson, and D. McGuinness. 2006. 'Using Ontario's Telehealth Health Telephone Helpline as an EarlyWarning System: A Study Protocol.' вмс Health Services Research 6 (1): $1-7$.

Svetovna zdravstvena organizacija. 2014. 'Zdravje 2020: temeljna evropska izhodišča za vsevladno in vsedružbeno akcijo za zdravje in blagostanje.' https://www.nijz.si/files/uploaded/health_2020_svn .pdf.

Triglav zdravstvena zavarovalnica. 2013. 'Proces obdelave zavarovalnih primerov.' Interno poročilo, Triglav zdravstvena zavarovalnica, Ljubljana.

- 2016. 'Poročilo ztč.' Interno poročilo, Triglav zdravstvena zavarovalnica, Ljubljana.

Wiener, J. A., and A. T. Gilliland. 2011. 'Balancing between Two Goods: Health Insurance Portability and Accountability Act and Ethical Compliancy Considerations for Privacy-Sensitive Materials in Health Sciences Archival and Historical Special Collections.' Journal of the Medical Library Association 99 (1): 15-22.

Zichello, C., and J. Sheridan. 2008. 'Occupational Health Nurses and Workers' Compensation Insurance Programs.' Aaohn Journal 56 (11): 455-58.

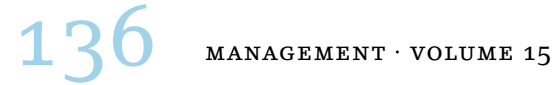

